\title{
TORCH Antibodies Among Pregnant Women and Their Newborns Receiving Care at Kilimanjaro Christian Medical Centre, Moshi, Tanzania
}

\author{
Aliasgher M Saajan, ${ }^{a, b}$ Mramba Nyindo, ${ }^{a, b}$ Joshua G Gidabayda, ${ }^{a, b}$ Mohammed S Abdallah, a,b \\ Shaneabbas H Jaffer, ${ }^{b}$ Aliasgher G Mukhtar, ${ }^{b}$ Tima M Khatibu, ${ }^{b}$ Rune Philemon, ${ }^{a, b}$ Grace D Kinabo, ${ }^{a, b}$ \\ Blandina T Mmbaga ${ }^{a, b, c}$ \\ a Department of Paediatrics and Child Health, Kilimanjaro Christian Medical Centre, Moshi, Tanzania; ${ }^{b}$ Kilimanjaro Christian Medical University College, Moshi,
Tanzania; ' ${ }^{\circ}$ ilimanjaro Clinical Research Institute, Moshi, Tanzania.
Correspondence to Aliasgher M Saajan (aliasghersajan@gmail.com).
}

\section{ABSTRACT}

Background: Toxoplasmosis, other (syphilis, varicella-zoster, parvovirus B19, and hepatitis B), rubella, cytomegalovirus (CMV), and herpes simplex virus type 1 and type 2 (HSV-1 and HSV-2) - known by the acronym TORCH - is a group of infections affecting both mothers and their unborn babies with adverse short- and long-term outcomes. The majority of infected mothers are asymptomatic, which leaves only speculation as to the probable cause of many congenital anomalies, stillbirths, prematurity, and death resulting from TORCH infections. The main objective of this study was to investigate previous exposure to TORCH infections by measuring the seroprevalence of TORCH antibodies in pregnant women and their newborns receiving care at Kilimanjaro Christian Medical Centre (KCMC), Moshi, Tanzania.

Methods: This was a cross-sectional, hospital-based study conducted at KCMC from December 2013 to April 2014. Of 350 pregnant women enrolled in the study, we tested 347 pregnant women attending the antenatal clinic and who opted to deliver at KCMC. Cord blood was collected and analysed for 309 of their newborns. To identify immunoglobulin G $(\mathrm{lgG})$ and immunoglobulin $M(\lg M)$ antibodies in mothers and $\lg M$ antibodies in newborns, we used enzyme-linked immunosorbent assay testing. A structured questionnaire was used to collect data of mothers and their newborns. Data analysis was done using SPSS version 20.

Results: The seroprevalence of $\lg G$ antibodies to TORCH infections among pregnant women was 154 (44.4\%) for toxoplasmosis, 311 (89.6\%) for rubella, 343 (98.6\%) for CMV, and 346 (99.7\%) for HSV-1 and HSV-2; 141 (40.6\%) had been exposed to all 4 infections. For HSV-1 and HSV-2, the $\lg M$ antibodies were found in 137 (39.5\%) of the 347 pregnant women included in this study. Age above 35 years (OR 6.15;95\% Cl, 1.22-31.1; $P=.028$ ) and multiparity IOR 1.63; 95\% Cl, 1.01-2.62; $P=.045$ ) were associated with higher risk of being exposed to all TORCH infections. A total of 11 newborns had IgM antibodies to HSV-1 and HSV-2 giving a seroprevalence of $3.6 \%$, and one newborn had IgM antibodies to rubella, giving a seroprevalence of $0.3 \%$. None of the newborns had antibodies to toxoplasmosis and CMV.

Conclusions: Exposure to TORCH infections was high among pregnant women in our population. Older age and multiparity were associated with a higher risk of being exposed to all TORCH infections. Seroprevalence to HSV- 1 and HSV-2 was high in newborns. The higher lgM antibodies to HSV-1 and HSV-2 among pregnant mothers and their newborns may disturb maternal, fetal, and neonatal health, and therefore we recommend establishing treatment protocol to support management of pregnant women and newborns who are seropositive for lgM antibodies.

\section{INTRODUCTION}

A wide range of microorganisms including bacteria, viruses, fungi, and protozoans may infect a pregnant woman and can lead to fetal death, organ injury, or short- and long-term sequelae depending on the offending pathogen. ${ }^{1}$ The classical group of microorganisms is known as TORCH, which includes 
toxoplasmosis, other (parvovirus B19, varicella-zoster virus infection, syphilis, hepatitis B), rubella, cytomegalovirus (CMV), and herpes simplex virus types 1 and 2 (HSV- 1 and HSV-2). ${ }^{2}$

These organisms acquired in utero can lead to resorption of the embryo, abortion, stillbirth, malformation, intrauterine growth restriction, prematurity, or sequelae of chronic postnatal infection. ${ }^{3}$ Infection acquired during the intrapartum or early postpartum period may result in severe systemic disease that leads to death or persistent postnatal infection.

In most cases, maternal illness due to TORCH infections is mild, but the impact on the developing fetus is more severe. ${ }^{4}$ Clinical evidence of TORCH infections may be seen at birth, soon afterwards, or not until weeks, months, or years later. This is exemplified by a study of a large cohort of newborns with congenital toxoplasmosis in Brazil, which showed high rates of early retinochoroidal lesions $(\sim 80 \%)$ and active lesions $(\sim 50 \%))^{5}$ Prevalence of toxoplasmosis based on the detection of immunoglobulin $\mathrm{G}$ ( $\operatorname{IgG}$ ) antibodies was reported to be $30.9 \%$ in the Mwanza Region of Tanzania. ${ }^{6}$ Worldwide, overall risk of transmission for congenital toxoplasmosis is reported to be $30 \%$ and increases with gestational age at maternal seroconversion, from less than $15 \%$ at 13 weeks of gestation to almost $71 \%$ at 36 weeks of gestation. Prevalence of congenital infection ranges from 0.1 to 0.3 per 1,000 live births. ${ }^{7}$ The classic triad of signs suggestive of congenital toxoplasmosis includes chorioretinitis, hydrocephalus, and intracranial calcifications. ${ }^{8}$

Worldwide, CMV seroprevalence among women of reproductive age ranges from $45 \%$ in higher-income countries to $100 \%$ in lower- and middle-income countries. ${ }^{9}$ According to a recent review of 11 studies, CMV seroprevalence of adolescents is $90 \%$ and $>95 \%$ during early adulthood and the average transmission rate is $0.65 \%$, ranging from $0.6 \%$ in Panama to $6.1 \%$ in China. ${ }^{10}$ The same review showed a range of $0 \%-29 \%$ classified as symptomatic CMV at birth. ${ }^{10}$ Another review of 15 studies found that long-term sequelae from congenital CMV occurred 3 to 4 times more in symptomatic infants $(40 \%-58 \%)$ compared with asymptomatic infants (13.5\%). More children with long-term sequelae from congenital CMV were asymptomatic at birth. ${ }^{11}$

In a study from 2011, CMV had been detected in about $20 \%$ of children in daycare centres, but CMV was also detected in about $10 \%$ of children who were not in daycare centres. ${ }^{12}$ In a 2017 study in China, a seroprevalence of $96.2 \%$ among pregnant women was reported with a CMV transmission rate ranging from $0.4 \%$ to $0.7 \%$ depending on the specimen screened. ${ }^{13}$ In a study from Japan in 2006, congenital CMV was directly responsible for a substantial proportion of early childhood sensorineural hearing loss, and almost half of the infants at risk for the development of late onset CMV or gap junction beta-2 protein associated sensorineural hearing loss showed no clinical or audiological indications at birth. ${ }^{14}$
Screening data from the Herpevac Trial for Women revealed that half $(51 \%)$ of participants screened had antibodies for HSV-1 (with or without HSV-2) and $11 \%$ had HSV-2 antibodies with or without HSV-1. ${ }^{15}$ The prevalence of antibodies to HSV-1 and HSV-2 increased with age, between the ages of 18 and 30. In Tanzania, HSV-2 seroprevalence was $80 \%$ among women at high risk in northwestern Tanzania, ${ }^{16} 20.7 \%$ among pregnant women in the rural Manyara and Singida regions, ${ }^{17}$ and $35 \%$ in Dar es Salaam. ${ }^{18}$ Neonatal HSV infection is acquired during 3 distinct periods: intrauterine (in utero 5\%), peripartum (during labour and delivery 85\%), and postpartum (postnatal $10 \%) .{ }^{19}$ Intrauterine infection is associated with severe HSV infection regardless of the timing of the acquisition during gestation; at birth, it is characterized by a triad of findings, including skin vesicles or scarring, eye damage, and severe manifestations of microcephaly or hydranencephaly. ${ }^{20}$ Data from the United States showed substantial utilization of resources for neonates with HSV. The median hospital charge was US\$37,431 (interquartile range US\$14,667-US\$74,559) per infant. ${ }^{21}$ The financial burden for congenital rubella syndrome is also substantial, estimated at US\$4,200 to US\$57,000 per case annually in middleincome countries and up to US\$140,000 over a lifetime in high-income countries. $^{22}$

Given the unfolding epidemiology, limited data, severe complications, and high economic burden of TORCH infections in the care of neonates with 1 or more of these infections, it is critical to thoroughly survey the distribution of TORCH infections in northern Tanzania. TORCH infections pose a substantial public health problem because the infected mothers are mostly asymptomatic, but the infections can lead to death, organ injury, or severe short- and long-term sequelae for their unborn fetuses and newborns. Thus, we aimed to study the immune status to congenital infections by TORCH agents among pregnant women and their newborns in northern Tanzania.

\section{METHODOLOGY}

\section{Study Design}

This was a cross-sectional study conducted from December 2013 to April 2014 at the Kilimanjaro Christian Medical Centre (KCMC), in Moshi, northern Tanzania. The study was conducted in the Obstetrics and Gynaecology Department and Paediatrics and Child Health Department using the antenatal clinic, labour ward, and neonatal ward. KCMC is a faith-based institution, primarily serving patients from the Kilimanjaro Region and neighbouring regions, such as Arusha, Manyara, Singida, and Tanga, as well as other parts of Tanzania. The number of hospital deliveries range from 3,500 to 4,000 per year, with more than half from the Moshi urban area and nearly $20 \%$ referred for medical reasons. $^{23}$ 


\section{Study Population}

All pregnant women above the age of 18 who attended the antenatal clinic during the study period, had a gestational age of at least 28 weeks (according to last menstrual period), and gave voluntary consent were enrolled in the study $(n=350)$. Pregnant women not planning to deliver at KCMC and those with emergency referrals for delivery were excluded. Of the 350 pregnant women enrolled in the study, 312 delivered at KCMC, 10 delivered at nearby health centres, and 28 were lost to follow-up (Figure 1).

\section{Sample Size Estimations}

The minimum sample size was estimated using a formula by the Survey System software package (1988), expressed as $\left[Z^{2} \cdot(p) \cdot(1-p)\right] / c^{2}$, where $Z=1.96$ for $95 \%$ confidence level (CI). A prevalence percentage $(\mathrm{p})$ of $35 \%$ was selected based on a study done in Dar es Salaam ${ }^{18}$ and c represented the minimal tolerable error at $95 \% \mathrm{CI}$, expressed as a decimal (.05). The minimum estimated sample size was 344 participants. The study therefore recruited 350 pregnant women and their infants (mother-infant pairs).

\section{Data Collection}

We collected sociodemographic, behavioural, clinical, and delivery data of mothers enrolled in the study using pretested data collection tools. Data collected included age, level of education, marital status, alcohol consumption, parity, mode of delivery, and related maternal and fetal outcomes.
After enrolment, a laboratory request form was administered. Approximately $4 \mathrm{ml}$ of whole blood was collected from each participant using BD Vacutainer blood collection redtop tubes (BD Medical, Plymouth, UK). Blood was allowed to clot for 1 hour and transported to Kilimanjaro Christian Research Institute - a biotechnology laboratory situated within the KCMC campus. Centrifugation was done at 1000-1300 g for 10 minutes. The supernatant (ie, serum) was transferred into cryotubes and stored in a refrigerator at $-70^{\circ} \mathrm{C}$ for later analysis. All newborns were followed up immediately after delivery and $2 \mathrm{ml}$ of cord blood were collected in BD Vacutainer blood collection red-top tubes for both liveborn and stillborn babies. The blood samples were processed and stored as described earlier.

\section{Laboratory Analysis}

Laboratory analysis was done at the Kilimanjaro Christian Research Institute. All blood samples and kit reagents were brought to room temperature $\left(23^{\circ} \mathrm{C}-25^{\circ} \mathrm{C}\right)$ before sample analysis was done. This was followed by testing for antibodies (IgG and $\operatorname{IgM}$ ) to toxoplasmosis, rubella, CMV, HSV-1, and HSV-2 using an enzyme-linked immunosorbent assay (ELISA) test kit for mothers and only immunoglobulin M (IgM) antibodies to TORCH for newborns, according to the manufacturer's instructions, as used for serum testing in this study.

\section{Assay Procedure for TORCH $\lg G$}

Ten microlitres $(10 \mu \mathrm{l})$ of blood sample were diluted with $1 \mathrm{ml}$ of sample diluent. For each standard, $100 \mu \mathrm{l}$ of diluted

\section{FIGURE 1. Number of Participants Recruited and Newborn Blood Samples Analysed}

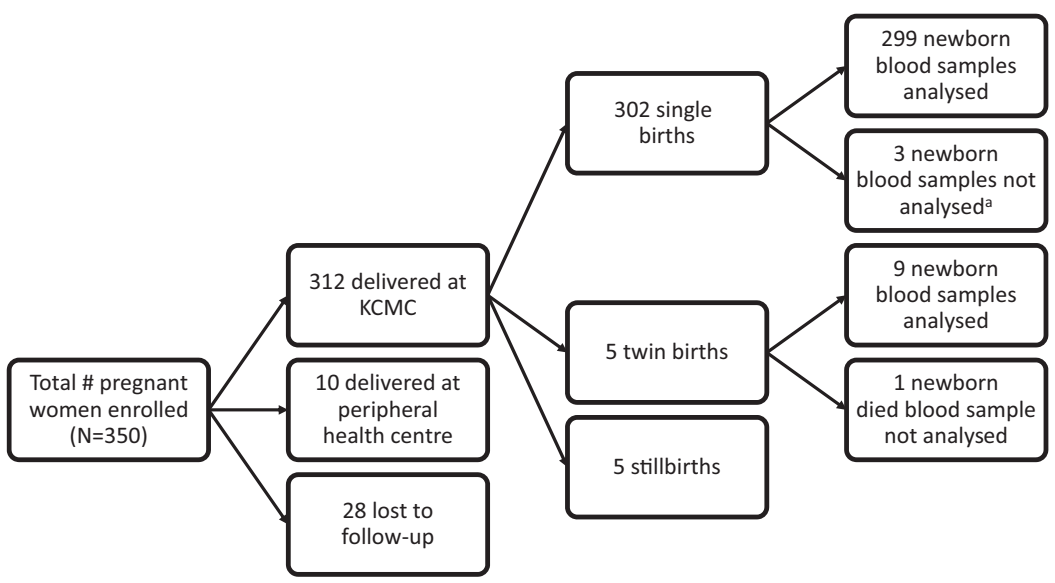

Abbreviations: KCMC, Kilimanjaro Christian Medical Centre.

aThe sample size was not sufficient and therefore was not analysed. 
test sera were added into microplate wells and covered with cardboard sealer. The microplate wells were incubated for 30 minutes at room temperature $\left(22^{\circ} \mathrm{C}-28^{\circ} \mathrm{C}\right)$. The plate covers were removed and contents discarded. The microplate wells were washed 5 times (each with $300 \mu \mathrm{L}$ of working wash solution). A $100 \mu$ l of conjugate solution was added into all wells and covered with cardboard sealer. The microplate wells were incubated for 30 minutes at room temperature $\left(22^{\circ} \mathrm{C}-28^{\circ} \mathrm{C}\right)$. The plate covers were removed and contents discarded. The microplate wells were washed 5 times. Each well was mixed with $100 \mu \mathrm{l}$ of chromogenic substrate solution and then incubated at room temperature in a dark room for 15 minutes. To stop the reaction, $100 \mu \mathrm{l}$ of stop solution was added to the wells. Absorbance was recorded at $450 \mathrm{~nm}$ by an ELISA reader.

\section{Assay Procedure for TORCH IgM}

We added $100 \mu \mathrm{l}$ of each control as well as diluted test sera into appropriate wells. Two consecutive wells in the first strip were considered blank and positive, respectively, and the next 2 wells for duplicate negative control serum. The microplate wells were covered with cardboard sealer tightly and incubated for 30 minutes at $37^{\circ} \mathrm{C}$. The plate covers were removed and contents discarded. The microplate wells were washed 5 times, each with $300 \mu$ of working wash solution. A $100 \mu$ conjugate solution was then added into all wells except the blank well. The microplate wells were covered with cardboard sealer tightly and incubated for 30 minutes at $37^{\circ} \mathrm{C}$. The plate covers were removed and contents discarded. The microplate wells were washed 5 times. Each well was mixed with $100 \mu \mathrm{l}$ of chromogenic substrate solution and then incubated at room temperature in a dark room for 15 minutes. To stop the reaction, $100 \mu \mathrm{l}$ of stop solution was added to the wells. Absorbance was recorded at $450 \mathrm{~nm}$ by an ELISA reader.

Validation of serological assays was done and the cut-off values for detection of IgG and IgM were calculated according to the manufacturer's instructions.

\section{Result Calculation and Evaluation for TORCH lgG}

To distinguish between positive and negative results, the serum/cut-off ratio (S/Co) index was used and calculated according to manufacturer's index cut-off value for this ELISA:

S/Co=sample optical density (OD)/cut-off value

(Cut-off value $=10$ antibody units per ml standard mean OD)

Based on this index, results higher than 1.1 were considered positive and results less than 0.9 were considered negative.

\section{Result Calculation and Evaluation for TORCH IgM}

To distinguish between positive and negative results, the cutoff index was determined by using the following formula as per the manufacturer manual:

$$
\begin{aligned}
& \text { Cut-off index }=\text { OD of sample/cut-off value } \\
& (\text { Cut-off value }= \\
& \text { mean OD of negative control serum }+0.15)
\end{aligned}
$$

\section{Statistical Analysis}

Data were analysed using IBM SPSS Statistics v. 20 (Armonk, New York, USA) where descriptive statistics were estimated. For combined TORCH infection, univariate analysis was done to estimate the odds ratios and the 95\% confidence interval to determine factors associated with exposure to both TORCH infections with $P<.05$ used as a cut-off value to indicate statistical significance.

\section{Ethical Consideration}

Ethical clearance was obtained from the Kilimanjaro Christian Medical University College via the College Research Ethics Review Committee and permission was obtained from KCMC Obstetrics and Gynaecology Department and Paediatrics and Child Health Department. Assent to participate and informed written consent was sought from each pregnant woman prior to involvement in the study.

\section{RESULTS}

\section{Sociodemographic Characteristics of the Study Participants}

The mean age of the pregnant women was 29 (standard deviation $[S D]=5.1$ ) years at enrolment, 191 participants (54.6\%) were between 21 and 30 years old, and $201(57.4 \%)$ participants were married. Most of the participants $(74.9 \%)$ had attended secondary education and the majority of them were living in urban areas $(89.1 \%)$. Table 1 shows the sociodemographic characteristics of the study participants.

\section{Behavioural, Clinical, and Delivery Characteristics of the Participants}

About $15 \%$ of the study participants reported to have consumed alcohol during the current pregnancy (Table 2). A total of $12(3.4 \%)$ pregnant women enrolled in this study were HIV positive. Fifty-nine percent tested negative for the venereal disease research laboratory syphilis test and $40.3 \%$ did not know their syphilis infection status. Regarding parity, $240(68.6 \%)$ participants were multiparous. The mean gestational age was 38.2 weeks $(S D=3.3)$. Regarding the mode of delivery, $187(60.1 \%)$ participants underwent spontaneous vaginal delivery and single live birth was the most common delivery outcome $(96.8 \%)$. No major postdelivery complications among mothers were reported. History of prolonged rupture of membrane was rare. 


\begin{tabular}{|c|c|c|}
\hline Characteristics & $\mathbf{n}$ & $\%$ \\
\hline \multicolumn{3}{|l|}{ Age in years } \\
\hline$\leq 20$ & 15 & 4.2 \\
\hline $21-30$ & 191 & 54.6 \\
\hline $31-40$ & 142 & 40.6 \\
\hline $41+$ & 2 & 0.6 \\
\hline Mean age in years (SD) & \multicolumn{2}{|c|}{$29.1(5.1)$} \\
\hline \multicolumn{3}{|l|}{ Marital status } \\
\hline Single & 2 & 0.6 \\
\hline Married & 201 & 57.4 \\
\hline Cohabiting & 147 & 42.0 \\
\hline \multicolumn{3}{|l|}{ Level of education } \\
\hline Primary education & 88 & 25.1 \\
\hline Secondary education and above & 262 & 74.9 \\
\hline \multicolumn{3}{|l|}{ Occupational status } \\
\hline Unemployed & 3 & 0.9 \\
\hline Self-employed & 144 & 41.5 \\
\hline Employed & 144 & 41.5 \\
\hline Housewife & 36 & 10.4 \\
\hline Student & 20 & 5.8 \\
\hline \multicolumn{3}{|l|}{ Residence } \\
\hline Rural & 38 & 10.9 \\
\hline Urban & 312 & 89.1 \\
\hline
\end{tabular}

Abbreviation: SD, standard deviation.

\section{Seroprevalence of $\lg G$ and $\lg M$ Antibodies to TORCH in Pregnant Women}

Overall, 141 (40.6\%) pregnant women participants were seropositive for all $4 \mathrm{TORCH}$ infections in our study. Ages above 35 years (OR 6.15; 95\% CI, 1.22-31.19; $P=.028$ ) and multiparity (OR 1.63; 95\% CI, 1.01-2.62; $P=.045$ ) were associated with a higher risk of seropositivity for all TORCH infections (Table 3).

Seroprevalence of IgG antibodies was as follows: toxoplasmosis $154(44.4 \%)$, rubella 311 (89.6\%), CMV $342(98.6 \%)$, and HSV-1 and HSV-2 (99.7\%) (Figure 2). Seroprevalence of IgM antibodies to HSV-1 and HSV-2 was $137(39.5 \%)$ (Figure 3).
TABLE 2. Behavioural, Clinical, and Delivery Characteristics of Participants

\begin{tabular}{|c|c|c|}
\hline Characteristics (n) & $\mathbf{n}$ & $\%$ \\
\hline \multicolumn{3}{|l|}{ Drug abuse or addiction (350) } \\
\hline Alcohol & 54 & 15.4 \\
\hline None & 296 & 84.6 \\
\hline \multicolumn{3}{|l|}{ HIV status (350) } \\
\hline Positive & 12 & 3.4 \\
\hline Negative & 331 & 94.6 \\
\hline Unknown & 7 & 2.0 \\
\hline \multicolumn{3}{|l|}{ Syphilis status (350) } \\
\hline Positive & 2 & 0.6 \\
\hline Negative & 207 & 59.1 \\
\hline Unknown & 141 & 40.3 \\
\hline \multicolumn{3}{|l|}{ Parity (350) } \\
\hline Nulliparous & 110 & 31.4 \\
\hline Multiparous & 240 & 68.6 \\
\hline Mean age in years at gestation (SD) & \multicolumn{2}{|c|}{$34.2(3.3)$} \\
\hline \multicolumn{3}{|l|}{ Place of delivery (350) } \\
\hline Kilimanjaro Christian Medical Centre & 312 & 89.0 \\
\hline Peripheral health centre & 10 & 2.9 \\
\hline Lost on follow-up & 28 & 8.0 \\
\hline \multicolumn{3}{|l|}{ Mode of delivery (31 1) } \\
\hline Spontaneous vaginal delivery & 187 & 60.1 \\
\hline Caesarean section & 124 & 39.9 \\
\hline \multicolumn{3}{|l|}{ Pregnancy outcomes (311) } \\
\hline Singleton live birth & 301 & 96.8 \\
\hline Multiple live births & 5 & 1.6 \\
\hline Stillbirth, macerated & 2 & 0.6 \\
\hline Stillbirth, fresh & 3 & 1.0 \\
\hline
\end{tabular}

Abbreviation: SD, standard deviation.

\section{Seroprevalence (IgM) Antibodies to TORCH in} Newborns

Seroprevalence of IgM antibodies to HSV-1 and HSV-2 among newborns was $11(3.6 \%)$. One newborn was coinfected with rubella, for a prevalence of $0.3 \%$ for rubella. 
TABLE 3. Maternal and Clinical Characteristics of Participants with lgG Antibodies to TORCH Infections Present (N=347)

\begin{tabular}{|c|c|c|c|c|}
\hline \multirow[b]{2}{*}{ Characteristics } & \multirow[b]{2}{*}{ Total } & \multicolumn{2}{|c|}{ All TORCH IgG } & \multirow[b]{2}{*}{$P$-value } \\
\hline & & n (\%) & OR $(95 \% \mathrm{Cl})$ & \\
\hline \multicolumn{5}{|l|}{ Age (years) } \\
\hline$\leq 20$ & 15 & $2(13.2)$ & Ref. & \\
\hline $21-35$ & 295 & $121(41.0)$ & $4.52(1.00-20.39)$ & .050 \\
\hline $36+$ & 37 & $18(48.6)$ & $6.15(1.22-31.19)$ & .028 \\
\hline \multicolumn{5}{|l|}{ Marital status } \\
\hline Single & 2 & $1(50.0)$ & $1.81(0.11-29.50)$ & .678 \\
\hline Married & 199 & $88(44.2)$ & $1.43(0.92-2.22)$ & .108 \\
\hline Cohabiting & 146 & $52(35.6)$ & Ref. & \\
\hline \multicolumn{5}{|l|}{ Level of education } \\
\hline Primary & 86 & $36(41.9)$ & $1.07(0.65-1.75)$ & .789 \\
\hline Secondary and above & 261 & $105(40.0)$ & Ref. & \\
\hline \multicolumn{5}{|l|}{ Occupational status } \\
\hline Unemployed & 3 & 1 (33.3) & $1.30(0.11-16.0)$ & .838 \\
\hline Self-employed & 144 & $67(46.5)$ & $2.26(1.02-5.03)$ & .045 \\
\hline Employed & 144 & $57(39.6)$ & $1.70(0.76-3.80)$ & .193 \\
\hline Housewife & 36 & $10(27.8)$ & Ref. & \\
\hline Student & 20 & $6(30.0)$ & $1.11(0.34-3.71)$ & .860 \\
\hline \multicolumn{5}{|l|}{ Residence } \\
\hline Rural & 36 & $14(38.9)$ & Ref. & \\
\hline Urban & 311 & $127(40.8)$ & $1.09(0.54-2.20)$ & .822 \\
\hline \multicolumn{5}{|l|}{ Parity } \\
\hline Nulliparous & 107 & 35 (32.7) & Ref. & \\
\hline Multiparous & 240 & $106(44.2)$ & $1.63(1.01-2.62)$ & .045 \\
\hline \multicolumn{5}{|l|}{ History of PROM } \\
\hline Yes & 10 & $3(30.0)$ & Ref. & \\
\hline No & 298 & $122(40.9)$ & $1.62(0.41-6.38)$ & .365 \\
\hline \multicolumn{5}{|l|}{ Mode of delivery } \\
\hline SVD & 188 & 71 (37.8) & Ref. & \\
\hline $\mathrm{C} / \mathrm{S}$ & 122 & $56(45.9)$ & $1.40(0.88-2.22)$ & .155 \\
\hline \multicolumn{5}{|l|}{ HIV status } \\
\hline Positive & 12 & $7(58.3)$ & $2.05(0.64-6.60)$ & .228 \\
\hline Negative & 328 & $133(40.5)$ & Ref. & \\
\hline Unknown & 7 & $1(14.3)$ & $0.24(1.03-2.05)$ & .194 \\
\hline \multicolumn{5}{|l|}{ Syphilis status } \\
\hline Positive & 2 & $2(100.0)$ & $2.86(0.000)$ & .999 \\
\hline Negative & 205 & $74(36.1)$ & Ref. & \\
\hline Unknown & 140 & $65(46.1)$ & $1.53(0.99-2.38)$ & .055 \\
\hline
\end{tabular}

Abbreviations: C/S, caesarean section; PROM, premature rupture of membrane; Ref., reference group; SVD, spontaneous vaginal delivery. 


\section{FIGURE 2. Prevalence of TORCH lgG Antibodies Among Participants, by Co-Infection}

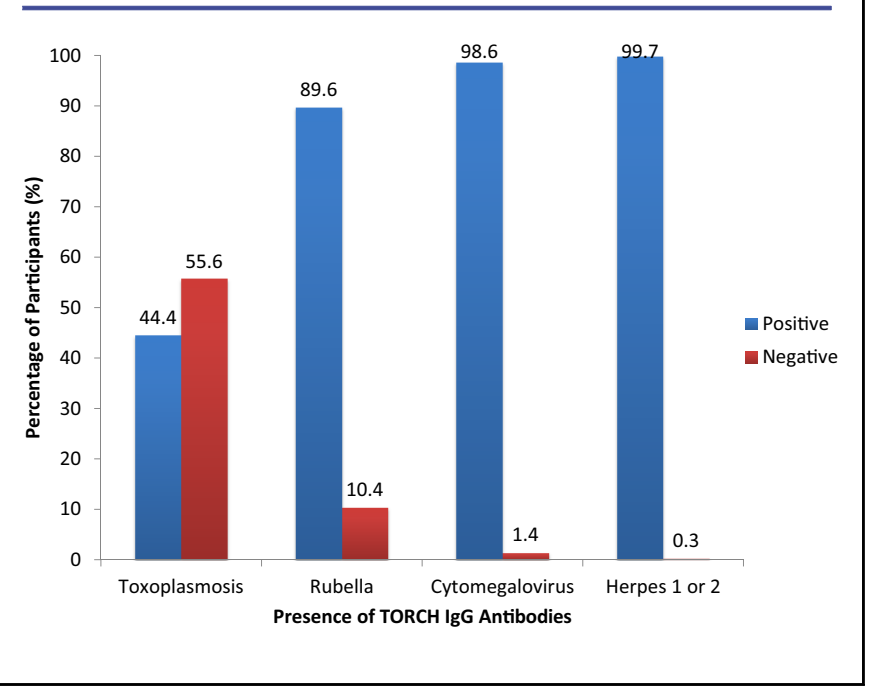

FIGURE 3. Prevalence of TORCH IgM Antibodies Among Participants, by Co-infection

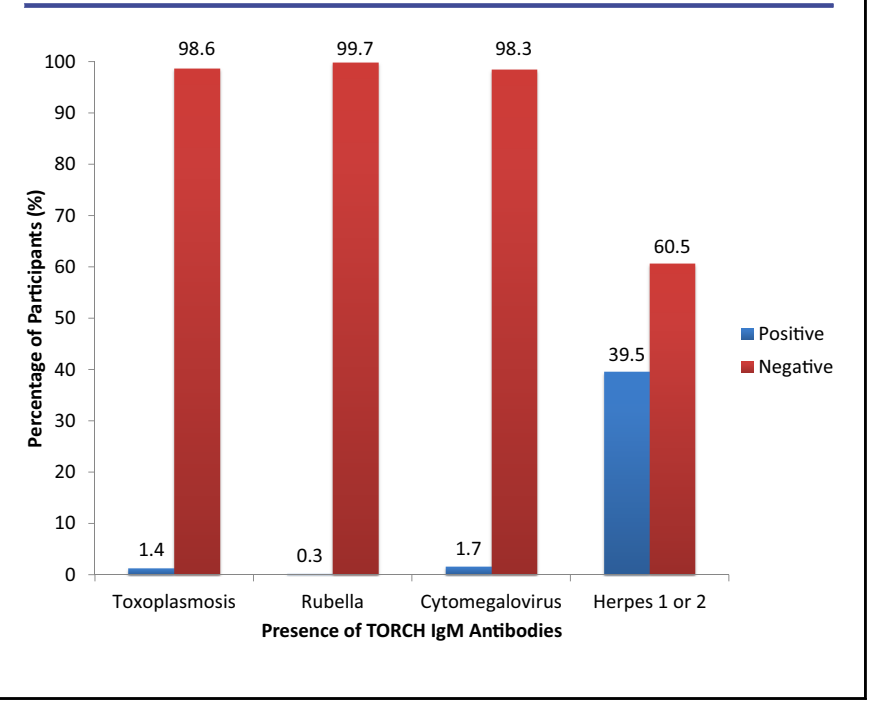

The mothers of 9 of the 11 newborns had previously been exposed to all TORCH infections investigated in this study: toxoplasmosis, rubella, CMV, and HSV-1 and HSV-2. All newborns who tested positive for IgM antibodies were single births, born with Apgar scores above 7, had no reported birth trauma or birth defects, had HIV-negative mothers, lived in urban areas, and their mothers had no history of premature

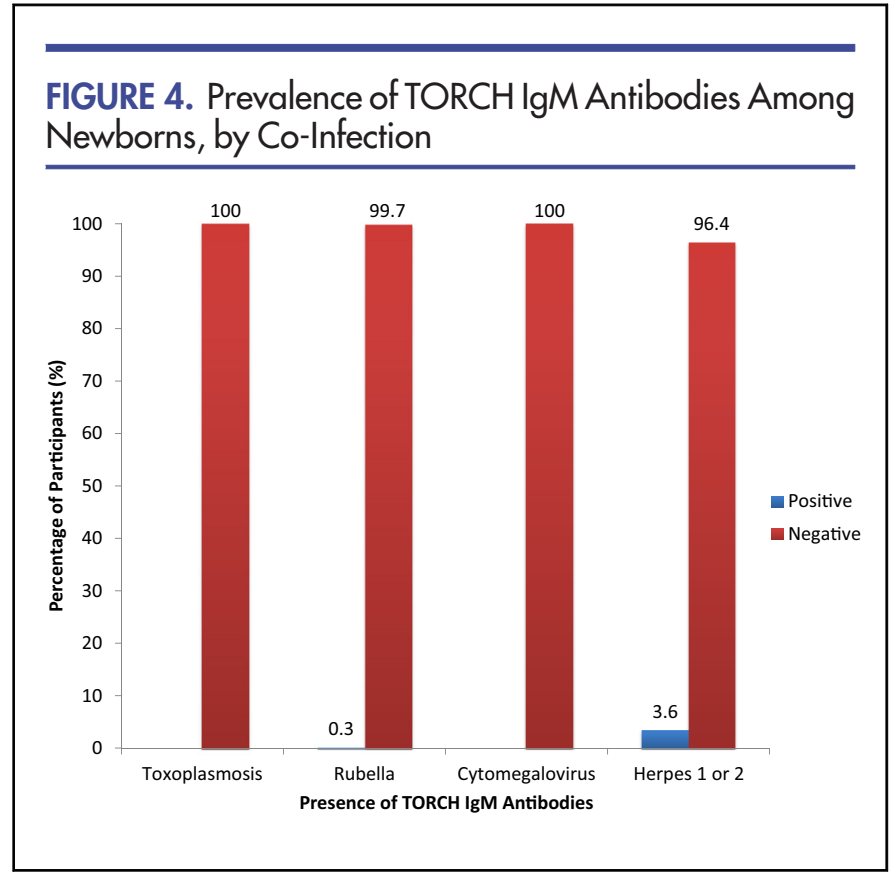

rupture of membranes during labour. None of the newborns were infected with toxoplasmosis or CMV (Figure 4).

\section{DISCUSSION}

The objective of this study was to investigate previous exposure to TORCH infections among pregnant women and their newborns receiving care at KCMC in Moshi, Tanzania, by measuring their levels of antibodies to the infections. Our findings showed a high seroprevalence of IgG antibodies to toxoplasmosis, rubella, CMV, and HSV-1 and HSV-2. A high seroprevalence of $\operatorname{IgM}$ antibodies to HSV may indicate ongoing infection, which increases risk of HSV transmission to the newborn. We also found that $3.6 \%$ of the newborns born to mothers with HSV tested positive for IgM antibodies, which indicates maternal intrauterine transmission. Overall, $40.6 \%$ of pregnant women were seropositive for all TORCH infections in this study. Higher exposure to these infections may therefore lead to concurrent infection, which could increase the chances of transmission, as observed in 9 of 11 newborns in this study who were HSV-positive and born to mothers who tested positive for IgG antibodies to all TORCH infections in this study. The higher IgG seroprevalence observed in this study in - which nearly all women were previously exposed to some TORCH infections - may indicate that women of reproductive age are exposed to the infections before pregnancy in the general population. This may support generalizability of the study findings; however, because it was a highly selective population of study participants in a tertiary care hospital, we must be cautious about generalizing the findings. 
Previous exposure to toxoplasmosis among pregnant women in our study was high, which could be attributed to geographical conditions, personal hygiene, eating habits, and lack of awareness of the disease before conception. Similar findings of seroprevalence for toxoplasmosis were reported in Colombia $(45.8 \%)^{24}$ and Albania $(48.6 \%){ }^{25}$ On the other hand, our findings showed a higher seroprevalence for TORCH infections than in Mexico $(8.2 \%),{ }^{26}$ the United Kingdom $(9.1 \%),{ }^{27}$ Japan $(10.3 \%),{ }^{28}$ Burkina Faso $(20.3 \%),{ }^{29}$ Palestine $(27.9 \%),{ }^{30}$ Croatia $(29.1 \%),{ }^{31}$ Kosovo $(29.4 \%),{ }^{32}$ Nigeria $(32.6 \%),{ }^{33}$ and Iran $(37.2 \%) .{ }^{34}$ More-over, our findings showed a higher seroprevalence than recently described by Mwambe and colleagues in Tanzania $(30.9 \%) .{ }^{6}$ Comparatively, our findings show a lower prevalence than reported in Saudi Arabia (51.4\%) and some parts of Brazil $(59.8 \%$ in Palotina and $60.6 \%$ among Jesuits). ${ }^{36}$ The variation of prevalence in different countries and regions may be attributed to geographical conditions, personal hygiene, eating habits, and lack of awareness of the disease. In our study, no newborn tested seropositive for antibodies to toxoplasmosis. The majority of newborns infected during pregnancy are asymptomatic at birth; however, $80 \%$ of them may develop long-term learning and visual disabilities later in their lives. ${ }^{37}$

Exposure to rubella before conception among pregnant women in this study was high, which may indicate a heavy circulation of wild-type rubella viruses in our population because widespread vaccination is not yet available in Tanzania. ${ }^{38}$ Moreover, infection of rubella virus leads to lifelong immunity. Similar trends of exposure to rubella were reported in Nigeria $(87.5 \%),{ }^{39}$ Tanzania $(92.9 \%),{ }^{40}$ Haiti $(93.4 \%),{ }^{41}$ Turkey $(93.8 \%),{ }^{42}$ and Croatia $(94.6 \%)^{31}$; however, our findings showed a higher prevalence to rubella than reported in Burkina Faso $(77 \%)^{43}$ and western Sudan $(65.3 \%){ }^{44}$

Exposure to CMV among pregnant women was also high in our study. The risk of CMV exposure to women of reproductive age increases when their child attends daycare ${ }^{12}$ and the fact that the majority of participants in our study were educated, employed, multiparous, and lived in urban areas, where the possibility of children attending daycare is high, may contribute to the high levels of exposure to CMV. Similarly high exposure rates were reported in Iran $(97.7 \%),{ }^{45}$ Nigeria $(97.2 \%),{ }^{46}$ Palestine $(96.6 \%),{ }^{47}$ and Taiwan $(91.1 \%)^{48}$; however, lower rates of exposure were reported in Croatia $(75.4 \%),{ }^{31}$ Norway $(62.8 \%),{ }^{49}$ and Tanzania $(63.1 \%)$ from a study in $1990 .^{50}$

Additionally, exposure to HSV-1 and HSV-2 among pregnant women in the study was high. This could be explained by the changing epidemiology of HSV disease toward HSV type-1 more than type-2, changing sexual behaviour, and the latency of HSV post-primary infection. Similar findings have been reported in the Republic of Vanuatu $(100 \%)^{51}$ and Croatia $(85.5 \%)^{32}$; however, lower exposures were reported in Norway $(14 \%),{ }^{18}$ Belgium
$(18.2 \%),{ }^{52}$ and in the Manyara and Singida regions of Tanzania $(20.7 \%) .{ }^{17}$ Parallel findings were seen among women with high risk reported in northern Tanzania. ${ }^{16}$ The risk of transmission of HSV-1 and HSV-2 to newborns was only from mothers with antibodies (ie, IgG and IgM antibodies to HSV-1 and HSV-2). This may be explained by acute maternal infection or reactivation of latent infection.

HSV was the only one with higher transmission rate $(3.6 \%)$, however, newborns were asymptomatic at birth and during the early neonatal period. A review of congenital herpes cases in the past 4 decades revealed that among 64 cases with clinical presentations, cutaneous lesions were the most common clinical manifestation where less than one-third of the cutaneous presentation had typical triad findings at birth, $44 \%$ had manifestations other than vesicles or bullae, $67 \%$ of patients had central nervous system manifestation and $39 \%$ patients had ocular findings, $18 \%$ of whom had retinal disease. ${ }^{53}$ Neonatal HSV infection is treated with acyclovir, $60 \mathrm{mg} / \mathrm{kg}$ of body weight per day in 3 doses (20 $\mathrm{mg} / \mathrm{kg}$ per dose) given intravenously. Disseminated and central nervous system infections are treated for at least 21 days. ${ }^{20}$ Currently, no treatment protocol exists at KCMC for newborns with HSV infection; therefore, no treatment is given for newborns who test HSV positive.

\section{Strengths and Limitations}

This study had a large sample size that included both pregnant women and their newborns. We were therefore able to estimate antibodies for 4 infections belonging to the TORCH group of infections and the transmission rate, primarily for HSV-land HSV-2.

Despite its strengths, this study also had some limitations. Limitations included a highly selective population of study participants because it was a hospital-based study in a tertiary care hospital, and therefore our findings might not reflect exposure in the general population. Second, the loss to follow-up of nearly $10 \%$ of newborns in our study means that we do not know their serostatus.

\section{CONCLUSIONS AND RECOMMENDATIONS}

Exposure to TORCH infections was very high among pregnant women in our study population. Newborn seroprevalence of IgM antibodies to HSV-1 and HSV-2 was also high. HSV- 1 and HSV-2 infections in pregnant women may disturb maternal, foetal, and neonatal health, and therefore, antenatal screening may be recommended. A large cohort study could help provide the evidence needed, including longterm sequelae for newborns who test positive for TORCH antibodies, in order to advocate for TORCH management during pregnancy and newborn care at KCMC.

HSV prevention advocacy to both partners during antenatal care is also recommended. Higher $\operatorname{Ig} M$ antibodies to HSV-1 and HSV-2 among pregnant women and their 
newborns indicate a need to establish treatment protocol to support management of pregnant women and newborns who are seropositive for IgM antibodies.

Acknowledgements: We appreciate the Medical Education Partnership Initiative (MEPI) from the Kilimanjaro Christian Medical University College and the Duke Global Health Institute for funding support through the HRSA award T84HA21123. Our appreciation to the former Head of Department of Obstetrics (Dr. Gilleard Massenga) who is currently the hospital Executive Director, all nurses and staffs at the Reproductive and Child Health Clinic, Obstetrics and Gynaecology Department, and Paediatrics and Child Health Department for support given during data collection. Finally, we would like to acknowledge the mother-infant pairs who agreed to participate in this study, and for their valuable information and cooperation throughout the study.

\section{REFERENCES}

1. Adams Waldorf KM, McAdams RM. Influence of infection during pregnancy on fetal development. Reproduction. 2013;146(5):R151-R162. CrossRef. Medline

2. Yadav RK, Maity S, Saha S. A review on TORCH: groups of congenital infection during pregnancy. J Sci Innov Res JSIR [Internet]. 2014;3(32):258-264. http:// www.jsirjournal.com/Vol3_Issue2_23.pdf

3. Maldonado Y, Nizet V, Klein JO, Remington JS, Wilson C. Current concepts of infections of the fetus and newborn infant. In: Remington JS, Klein JO, Wilson C, Nizet V, Maldonado Y, eds. Infectious Diseases of the Fetus and Newborn Infant. 7th ed. Philadelphia, Pennsylvania, USA: Saunders; 2010. p. 2-23.

4. Boyer SG, Boyer KM. Update on TORCH infections in the newborn infant. Newborn Infant Nurs Rev. 2004;4(1):70-80. CrossRef

5. Vasconcelos-Santos DV, Machado Azevedo DO, Campos WR, et al; UFMG Congenital Toxoplasmosis Brazilian Group. Congenital toxoplasmosis in southeastern Brazil: results of early ophthalmologic examination of a large cohort of neonates. Ophthalmology. 2009;1 16(1 1):2199-2205.e1. CrossRef. Medline

6. Mwambe B, Mshana SE, Kidenya BR, et al. Sero-prevalence and factors associated with Toxoplasma gondii infection among pregnant women attending antenatal care in Mwanza, Tanzania. Parasit Vectors. 2013;6(1):222. CrossRef. Medline

7. Kieffer F, Wallon M. Congenital toxoplasmosis. Handb Clin Neurol. 2013;112:1099-1101. CrossRef. Medline

8. Jones J, Lopez A, Wilson M. Congenital toxoplasmosis. Am Fam Physician. 2003;67(10):2131-2138. Medline

9. Plosa EJ, Esbenshade JC, Fuller MP, Weitkamp JH. Cytomegalovirus infection. Pediatr Rev. 2012;33(4):156-163, quiz 163. CrossRef. Medline

10. Lanzieri TM, Dollard SC, Bialek SR, Grosse SD. Systematic review of the birth prevalence of congenital cytomegalovirus infection in developing countries. Int J Infect Dis. 2014;22:44-48. CrossRef

11. Dollard SC, Grosse SD, Ross DS. New estimates of the prevalence of neurological and sensory sequelae and mortality associated with congenital cytomegalovirus infection. Rev Med Virol. 2007;17(5):355-363. CrossRef. Medline

12. Cannon MJ, Hyde TB, Schmid DS. Review of cytomegalovirus shedding in bodily fluids and relevance to congenital cytomegalovirus infection. Rev Med Virol. 2011;21(4):240-255. CrossRef. Medline

13. Wang $S$, Wang $T$, Zhang $W$, et al. Cohort study on maternal cytomegalovirus seroprevalence and prevalence and clinical manifestations of congenital infection in China. Medicine (Baltimore). 2017;96(5):e6007. CrossRef

14. Ogawa H, Suzutani $\mathrm{T}$, Baba $\mathrm{Y}$, et al. Etiology of severe sensorineural hearing loss in children: independent impact of congenital cytomegalovirus infection and GJB2 mutations. J Infect Dis. 2007;195(6):782-788. CrossRef. Medline

15. Schulte JM, Bellamy AR, Hook EW III, et al. HSV-1 and HSV-2 seroprevalence in the United States among asymptomatic women unaware of any herpes simplex virus infection (Herpevac Trial for Women). South Med J. 2014;107(2):79-84. CrossRef. Medline

16. Watson-Jones $D$, Weiss HA, Rusizoka $M$, et al. Risk factors for herpes simplex virus type 2 and HIV among women at high risk in northwestern Tanzania: preparing for an HSV-2 intervention trial. J Acquir Immune Defic Syndr. 2007;46(5):631-642. CrossRef. Medline
17. Yahya-Malima KI, Evjen-Olsen B, Matee MI, Fylkesnes K, Haarr L. HIV-1, HSV-2 and syphilis among pregnant women in a rural area of Tanzania: prevalence and risk factors. BMC Infect Dis. 2008;8(1):75. CrossRef. Medline

18. Nilsen A, Mwakagile D, Marsden H, Langeland N, Matre R, Haarr L. Prevalence of, and risk factors for, HSV-2 antibodies in sexually transmitted disease patients, healthy pregnant females, blood donors and medical students in Tanzania and Nonway. Epidemiol Infect. 2005;133(05):915-925. CrossRef. Medline

19. Kimberlin DW. Herpes simplex virus infections of the newborn. Semin Perinatol. 2007;31(1):19-25. CrossRef. Medline

20. Gutierrez KM, Whitley RJ, Arvin AM. Herpes simplex virus infections. In: Remington J, Klein J, Wilson C, Nizet V, Maldonado Y, eds. Infections Diseases of the Fetus and Newborn Infant. 7th ed. Philadelphia, Pennsylvania, USA: Saunders; 2010: 813-833.

21. Ambroggio L, Lorch SA, Mohamad Z, Mossey J, Shah SS. Congenital anomalies and resource utilization in neonates infected with herpes simplex virus. Sex Transm Dis. 2009;36(1 1):680-685. CrossRef. Medline

22. Babigumira JB, Morgan I, Levin A. Health economics of rubella: a systematic review to assess the value of rubella vaccination. BMC Public Health. 2013;13(1):406. CrossRef. Medline

23. Mahande MJ, Daltveit AK, Obure J, et al. Recurrence of preterm birth and perinatal mortality in northern Tanzania: registry-based cohort study. Trop Med Int Health. 2013;18(8):962-967. CrossRef. Medline

24. Rosso F, Les JT, Agudelo A, et al. Prevalence of infection with Toxoplasma gondii among pregnant women in Cali, Colombia, South America. Am J Trop Med Hyg. 2008;78(3):504-508. Medline

25. Maggi $P$, Volpe A, Carito V, et al. Surveillance of toxoplasmosis in pregnant women in Albania. New Microbiol. 2009;32(1):89-92. Medline

26. Alvarado-Esquivel C, Campillo-Ruiz F, Liesenfeld O. Seroepidemiology of infection with Toxoplasma gondii in migrant agricultural workers living in poverty in Durango, Mexico. Parasit Vectors [Internet]. 2013;6:113. CrossRef. Medline

27. Nash JQ, Chissel S, Jones J, Warburton F, Verlander NQ. Risk factors for toxoplasmosis in pregnant women in Kent, United Kingdom. Epidemiol Infect. 2005;133(3):475-483. CrossRef. Medline

28. Sakikawa $M$, Noda $S$, Hanaoka $M$, et al. Anti-Toxoplasma antibody prevalence, primary infection rate, and risk factors in a study of toxoplasmosis in 4,466 pregnant women in Japan. Clin Vaccine Immunol. 2012;19(3):365-367. CrossRef. Medline

29. Linguissi L. Seroprevalence of toxoplasmosis and rubella in pregnant women attending antenatal private clinic at Ouagadougou, Burkina Faso. Asian Pac J Trop Med. 2012;5(10):810-813. CrossRef. Medline

30. Nijem KA, Al-Amieh S. Seroprevalence and associated risk factors of toxoplasmosis in pregnant women in Hebron district, Palestine. East Mediterr Health J. 2009;15(5): 1278-1284. Medline

31. Vilibic-Cavlek T, Liubin-Sternak S, Ban M, Kolaric B, Sviben M, Mlinaric-Galinovic $G$. Seroprevalence of TORCH infections in women of childbearing age in Croatia. J Matern Fetal Neonatal Med. 201 ;24(2):280-283. CrossRef. Medline

32. Dentico $P$, Volpe A, Putoto $G$, et al. Toxoplasmosis in Kosovo pregnant women. New Microbiol. 2011;34(2):203-207. Medline

33. Deji-Agboola A, Busari O, Osinupebi O, Amoo A. Seroprevalence of Toxoplasma gondii antibodies among pregnant women attending antenatal clinic of federal medical center, Lagos, Nigeria. Int J Biol Med Res. 2011 ;2(4):1135-1139.

34. Hajsoleimani F, Ataeian A, Nourian A, Mazloomzadeh S. Seroprevalence of Toxoplasma gondii in pregnant women and bioassay of IgM positive cases in Zanjan, Northwest of Iran. Iran J Parasitol. 2012;7(2):82-86. Medline

35. Mohammad HA, Amin TT, Balaha MH, Moghannum MSA. Toxoplasmosis among the pregnant women attending a Saudi maternity hospital: seroprevalence and possible risk factors. Ann Trop Med Parasitol. 2010;104(6):493-504. CrossRef. Medline

36. Bittencourt LH, Lopes-Mori FM, Mitsuka-Breganó R, et al. Seroepidemiology of toxoplasmosis in pregnant women since the implementation of the Surveillance Program of Toxoplasmosis Acquired in Pregnancy and Congenital in the western region of Paraná, Brazil. Rev Bras Ginecol Obstet. 2012;34(2):63-68. Medline

37. Jones JL, Kruszon-Moran D, Wilson M, McQuillan G, Navin T, McAuley JB. Toxoplasma gondii infection in the United States: seroprevalence and risk factors. Am J Epidemiol. 2001;154(4):357-365. CrossRef. Medline 
38. United Republic of Tanzania, Ministry of Health and Social Welfare. The National Road Map Strategic Plan to Accelerate Reduction of Maternal, Newborn and Child Deaths in Tanzania, 2008-2015. Dar es Salaam, Tanzania: Ministry of Health and Social Welfare; 2008. http://can-mnch.ca/wp-content/uploads/2013/09/ Tanzania-National-Road-Map-Strategic-Plan.pdf

39. Kolawole OM, Anjorin EO, Adekanle DA, Kolawole CF, Durowade KA. Seroprevalence of rubella lgG antibody in pregnant women in Osogbo, Nigeria. Int J Prev Med. 2014;5(3):287-292. Medline

40. Mwambe B, Mirambo MM, Mshana SE, et al. Sero-positivity rate of rubella and associated factors among pregnant women attending antenatal care in Mwanza, Tanzania. BMC Pregnancy Childbirth. 2014;14(1):95. CrossRef. Medline

41. Fitter DL, Anselme R, Paluku G, et al. Seroprevalence of measles and rubella antibodies in pregnant women Haiti, 2012. Vaccine. 2013;32(1):69-73. CrossRef. Medline

42. Pehlivan E, Karaoglu L, Ozen $M$, et al. Rubella seroprevalence in an unvaccinated pregnant population in Malatya, Turkey. Public Health. 2007;121(6):462-468. CrossRef. Medline

43. Linguissi LSG, Nagalo BM, Bisseye C, et al. Seroprevalence of toxoplasmosis and rubella in pregnant women attending antenatal private clinic at Ouagadougou, Burkina Faso. Pac J Trop Med. 2012;5(10):810-813. CrossRef. Medline

44. Hamdan HZ, Abdelbagi IE, Nasser NM, Adam I. Seroprevalence of cytomegalovirus and rubella among pregnant women in western Sudan. Virol J. 201 1;8(1):217. Medline

45. Tabatabaee M, Tayyebi D. Seroepidemiologic study of human cyłomegalovirus in pregnant women in Valiasr Hospital of Kazeroon, Fars, Iran. J Matern Fetal Neonatal Med. 2009;22(6):517-521. CrossRef. Medline

46. Akinbami A, Rabiu KA, Adewumi, et al. Seroprevalence of cytomegalovirus antibodies amongst normal pregnant women in Nigeria. Int $J$ Womens Health 2011;3:423-428. CrossRef. Medline

47. Neirukh T, Qaisi A, Saleh N, et al. Seroprevalence of cytomegalovirus among pregnant women and hospitalized children in Palestine. BMC Infect Dis. 2013;13(1):528. CrossRef. Medline

48. Chen $\mathrm{MH}$, Chen $\mathrm{PC}$, Jeng $\mathrm{SF}$, et al. High perinatal seroprevalence of cytomegalovirus in northern Taiwan. J Paediatr Child Health. 2008;44(4):166-169. CrossRef. Medline
49. Barlinn R, Vainio K, Samdal HH, Nordbø SA, Nøkleby H, Dudman SG. Susceptibility to cytomegalovirus, parvovirus B19 and age-dependent differences in levels of rubella antibodies among pregnant women. J Med Virol. 2014;86(5):820-826. CrossRef. Medline

50. Mhalu F, Haukenes $G$. Prevalence of cytomegalovirus antibody in pregnant women, AIDS patients and STD patients in Dar es Salaam. AIDS. 1990;4(12):1294-1295. CrossRef. Medline

51. Haddow $\amalg$, Sullivan EA, Taylor J, et al. Herpes simplex virus type 2 (HSV-2) infection in women attending an antenatal clinic in the South Pacific island nation of Vanuatu. Sex Transm Dis. 2007;34(5):258-261. Medline

52. Bodéus M, Laffineur K, Kabamba-Mukadi B, Hubinont C, Bernard P, Goubau P. Seroepidemiology of herpes simplex type 2 in pregnant women in Belgium. Sex Transm Dis. 2004;31(5):297-300. CrossRef. Medline

53. Marquez L, Levy ML, Munoz FM, Palazzi DL. A report of three cases and review of intrauterine herpes simplex virus infection. Pediatr Infect Dis J. 2011:30(2):153157. CrossRef. Medline

\section{Peer Reviewed}

Competing Interests: None declared.

Received: 27 Oct 2016; Accepted: 1 Aug 2017

Cite this article as: Saajan AM, Nyindo M, Gidabayda JG, Abdallah MS, Jaffer SH, Mukhtar AG, et al. TORCH Antibodies Among Pregnant Women and Their Newborns Receiving Care at Kilimanjaro Christian Medical Centre, Moshi, Tanzania. East African Health Res J. 2017;1(2):95-104. https://doi.org/10.24248/EAHRJ-D-1600340

(c) Saajan et al. This is an open-access article distributed under the terms of the Creative Commons Attribution License, which permits unrestricted use, distribution, and reproduction in any medium, provided the original author and source are properly cited. To view a copy of the license, visit http://creativecommons.org/licenses/by/3.0/. When linking to this article, please use the following permanent link: https://doi.org/ 10.24248/EAHRJ-D-16-00340 